\title{
Dr Schuss isch duss!
}

Kuum isch in Basel d Wienachtszyt verklunge, kuum het me d Gschänggli umduscht oder au verruumt, kuum het men alli Wienachtslieder gsunge, und no bevoor dr Schämpis am Sylveschter schuumt, deerf me beraits an näggschte Fyrtig dängge.

Wemme derno daas Gribblen gspyyrt und au dä Drang, ka me d Blaggedde sich an s Revers hängge, fir dass me gseet und waiss: Es goot jetz nimme lang. So schaare d Bebbi all Joor wie vergiftet;

Sy warten uff dä eerscht vorfaasnächtlig Gruess und Gnuss. Und wird s glai Ghaimnis ändlig fyyrlig gliftet, dernoo waiss jeede Faasnachts-Naar: Dr Schuss isch duss! Kurz voor dr Faasnacht daas Joor derf me hoffe, dass in Sant Jokeb au s ney Stadioon feertig stoot. Drum glaube mer, mer haige s richtig Sujet droffe mit dr Blaggedde Zwai-Null-Ains vom Magnus Roth. Im Joggeli, doo gseet men alli Soorte vo Fään, wo als zem FCB an d Schutt-Mätsch geen. Drum sinn s daas Joor grad drey Blaggedde woorde mit dreyerlai Figuure, wo an d Balle schleen: Im Kupfer isch s e scheeni Alti Dante,

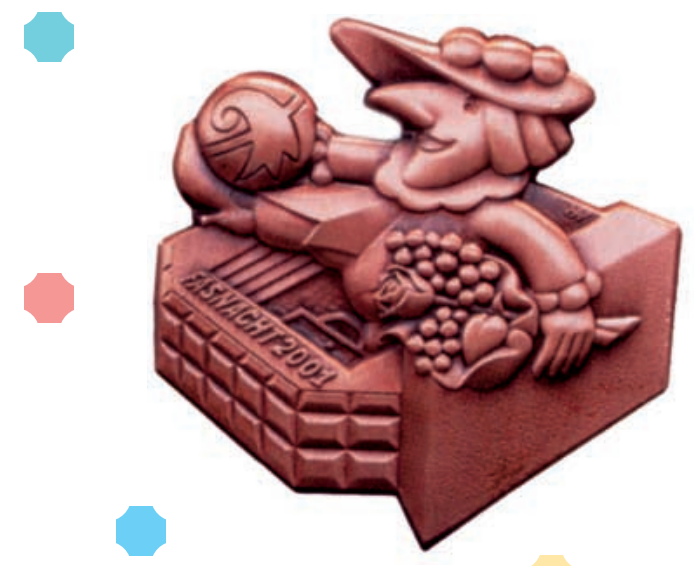
e feyne Harlekin im Silber, und im Gold, brobiert s e Waggis iber d Stadioon-Kante, dass d Balle voll als Dräffer zmitts ins Schwarze rollt. Am beschte kauft me drum vo alle Soorte, denn alli Bryyse sinn - mer hoffe, dass s sich loont au daasmool noonig uffegschryyblet woorde.

Es blybt bi säggs, bi zwelf und vierzig Stai - wie gwoont.

Zem säggstemool gits daas Joor au e Litho-Helge, fir dass men iber s Joor und non e langi Zyt vo dääre Faasnacht ganz e bitz ka schwelge: Mit 120 Franggen isch me bi de Lyt ...

Im René und im Däni Müller wämmer

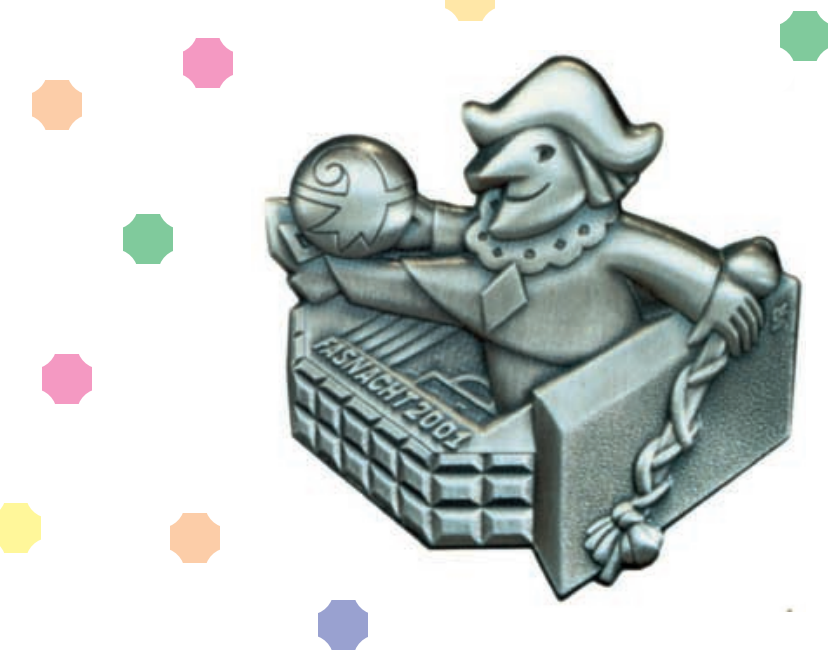
e hä̈rzlig Danggscheen saage fir d Blaggedde hit. Dr ander gaischtig Blueme-Maie gämmer im Peter Schleiss fir s brächtig groote Litho mit.

Vom säggste Jänner aa ka men am Graage

d Blaggedde, oder au grad alli drey - persee zem Zaiche vo dr groosse Voorfraid fraidig draage.

Es gheert sich z Baasel!

S Fasnachts-Comité
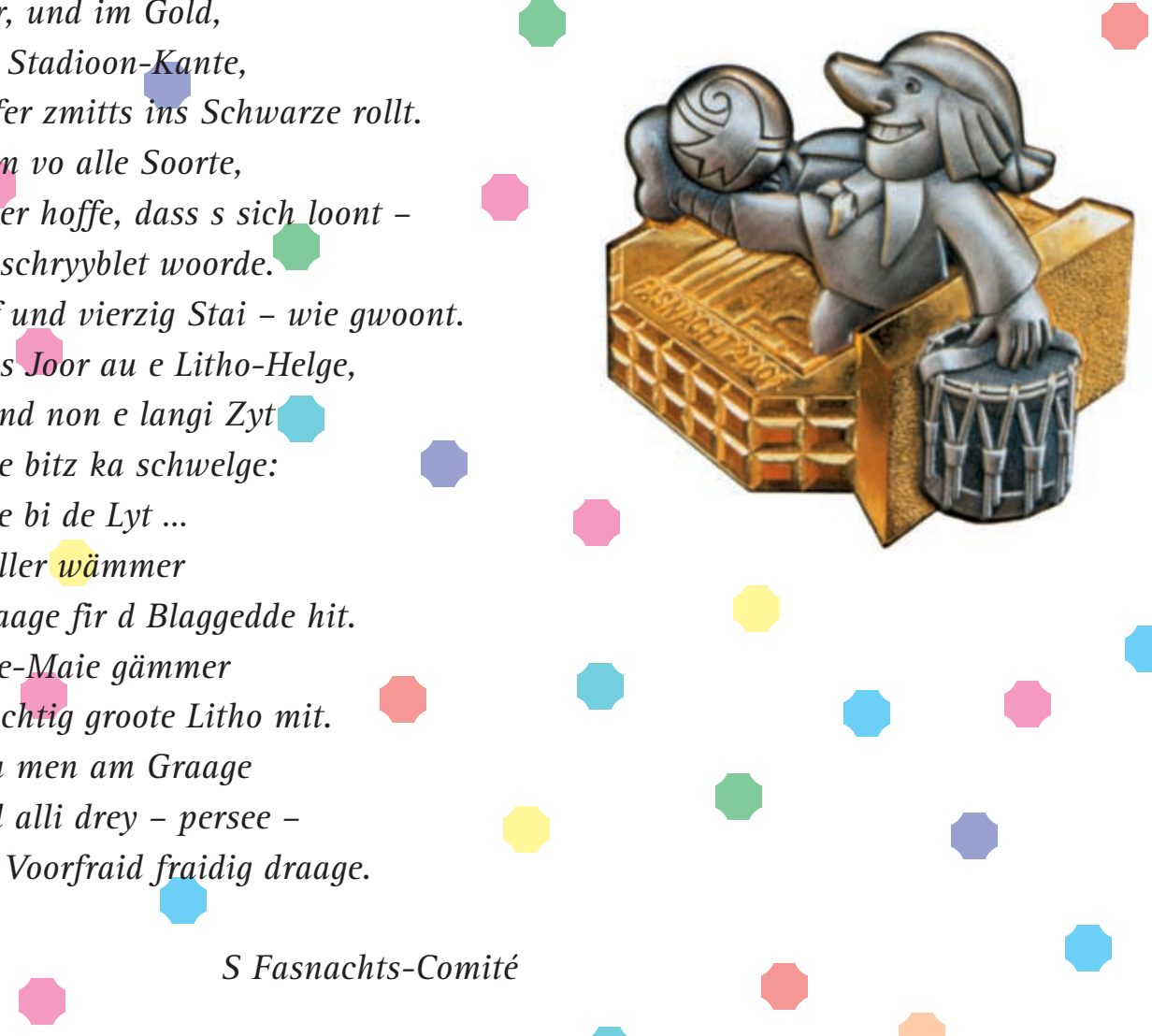